\title{
Assessment of Index Case Family Testing Among Adults Attending Art Clinic at Kule Refugee Camp, Southwest Ethiopia: 2021
}

\author{
Yohannes Wegu' \\ Tesfaye Sileshi' \\ Tamirat Melis ${ }^{2}$ \\ 'Department of Public Health, College of \\ Medicine \& Health Sciences, Metu \\ University, Metu, Ethiopia; ${ }^{2}$ Department \\ of Public Health, College of Medicine \& \\ Health Sciences, Wolkite University, \\ Wolkite, Ethiopia
}

Background: Human immune virus testing and counseling is the gateway to accessing antiretro viral treatment. As a priority population group, families of index clients have been largely neglected due to a number of different factors. Testing sexual partners and children of human immunodeficiency virus (HIV) positive persons (index case finding) is a promising way of identifying HIV-positive persons unaware of their HIV status.

Objective: The aim of this study was to determine the proportion of index case family testing and its associated factors among adults attending an ART clinic at Kule Refugee Camp, southwestern Ethiopia, 2021.

Methods and Materials: An institution-based cross-sectional study was conducted at Kule Refugee Camp, Gambela region. A total of 348 adult ART clinic attendants were selected by using systematic random sampling technique. Data were collected by using a pre-tested interviewer-administered semi-structured questionnaire. The collected data were entered into Epi-Data 3.1 and exported to SPSS version 23. Bivariable and multivariable logistic regression analyses were used to identify factors associated with index case family testing. The strength of association was assessed by adjusted odds ratio, and statistical significance was declared at a $p$-value $<0.05$ and $95 \%$ CI.

Results: The proportion of index case family testing was 49.\%. Educational level: primary level $(\mathrm{AOR}=2.4,95 \% \mathrm{CI}=1.24-4.42)$, secondary level and above $(\mathrm{AOR}=2.6,95 \% \mathrm{CI}=1.20$ 4.70), ART adherence $(\mathrm{AOR}=6,95 \% \mathrm{CI}=2.8-14.1)$, years on $\mathrm{ART}(\mathrm{AOR}=2,95 \% \mathrm{CI}=1.10$ 3.20 ), discussion about $\mathrm{HIV}$ testing ( $\mathrm{AOR}=3.6,95 \% \mathrm{CI}=1.30-10.30)$, disclosure status (AOR 6, 95\% CI=2.21-16.94), and being tested through voluntary counseling and testing $(A O R=3.0,95 \%$ CI1.70-5.70) were factors significantly associated with index case family HIV testing.

Conclusion and Recommendations: This study revealed that the proportion of index case family HIV testing in Kule Refugee Camp was 49\%. Educational status, adherence status, disclosure status, years on ART, and voluntary counseling and testing were determinant factors. Health professionals should advise index cases to adhere to ART drugs, to disclose their HIV status to their families, and should provide counseling based on guidelines.

Keywords: index case testing, refugee, HIV/AIDS, associated factors

\section{Background}

Human immunodeficiency virus testing and counseling is the gateway to accessing anti-retroviral treatment, which reduces rates of morbidity and mortality and motivates individuals to modify risky behaviours, as well as preventing
Correspondence: Tamirat Melis

Email tamiratmelis27@gmail.com 
transmission by suppression of viral load among people living with HIV (PLHIV) on ART. ${ }^{1}$ In 2014, UNAIDS introduced the 90-90-90 targets, an ambitious treatment target to help end the AIDS epidemic by 2030, so that $90 \%$ of people living with HIV should know their status, $90 \%$ of those should be on treatment, and $90 \%$ of those should have a controlled viral load by $2020 .^{2}$ Index family testing is promoted because it has a high yield positivity, improves testing coverage, improves ART retention, and offers a convenient service for families affected by HIV irrespective of the background of HIV prevalence in the country. ${ }^{3}$ Nationally, in 2016, the proportion of HIV testing among index cases of males and females was 78.95 and $78.3 \%$, respectively. However, the proportion of children tested for HIV was only $6 \%{ }^{3}$

HIV infection remains one of the world's most serious public health and medical concerns; it is especially severe in sub-Saharan Africa. Globally, there were 37.9 million people living with HIV at the end of 2018. Of the global prevalence of HIV, sub-Saharan Africa constitutes nearly two-thirds of cases. ${ }^{4,5}$ In 2019 , there were an estimated 1.5 million people newly-infected with HIV and $67.5 \%$ were in sub-Saharan Africa. Although AIDS-related deaths decreased globally by $48 \%$ between 2005 and 2017, AIDS-related deaths among adults and children totaled 690,000 and $63 \%$ of this global death was in subSaharan Africa. ${ }^{4}$

Based on the nature and dynamicity of the epidemic, the current testing coverage is lower relative to need. ${ }^{6}$ Vulnerable populations experience multiple challenges to accessing services, including language barriers, limited access to healthcare services, stigma, discrimination, poverty, and limited information about HIV infection and treatment. ${ }^{6}$

Although HIV testing services are key for HIV prevention, treatment, and support, globally $30 \%$ (one in five) of PLHIV are still unaware they are infected. This number varies regionally, in North America and Europe 15\%, in Asia and Pacific countries 29\%, in Caribbean countries $34 \%$, in Western and North Africa 42\%, and in Eastern and South Africa $26 \%$ of people living with HIV do not know their status. 5,7

According to a CDC report from 2016-2018, about 1,700,998 persons were tested for HIV using contact index testing among 20 countries. From those tested, $5.8 \%$ were reported as HIV-positive, including 9.8\% aged $\geq 15$ years and $1.5 \%$ aged $<15$ years. ${ }^{6}$
The 2018 Ethiopian population-based HIV Impact Assessment (EPHIA) estimated an urban HIV prevalence of $3.0 \%$. The highest was in Gambela, which was $5.7 \%$, and the lowest was in southern nation nationalities, which was $1.8 \%$. The prevalence of HIV among children aged 0 14 years in urban Ethiopia was $0.3 \%$ and the prevalence of HIV among partners of PLHIV was $28 \%{ }^{8,9}$

Although index case family testing is a key strategy to identify those most at risk of acquiring HIV with a high yield of positive cases, data about index case family testing is lacking for refugee settings. Therefore, the aim of this study was to assess the proportion of index case family testing and its factors associated at kule refugee camp, Gambela, Ethiopia, 2021.

\section{Methods}

\section{Study Setting and Design}

This study was conducted at Kule Refugee Camp, which is one of the seven refugee camps in Gambela Region and was established in May 2014 in response to the major refugee influx from South Sudan. It is located $50 \mathrm{~km}$ from Gambela town and $766 \mathrm{~km}$ from Addis Ababa.

According to the UNHCR 2020 report the total refugee population in Kule Camp was 45,397. Among these, 45\% were male, $55 \%$ females, with $63 \%$ of the population under the age of 18 years. The camp is organized as seven zones led by zonal leaders selected by the refugees. Medicine Sans Frontiers Holland (MSF-H) provides a comprehensive medical service. HIV care service is among the prioritized medical services and has 1,355 registered ART clients under three ART clinics. According to the 2020 GC HIS report, HIV testing and counseling service performance for the camp is $11.1 \%$. The study was conducted from March to July 2021 among ART clinic attendees in Kule Refugee Camp. A cross-sectional study design was used. The study populations were all HIV positive adult patients who were attending an ART clinic at Kule Refugee Camp that fulfill the eligibility criteria. All adult individuals who were receiving anti-retro viral therapy and whose age was greater than 15 years were included in the study, while those clients who were seriously ill or those who had mental illness were excluded from the study.

\section{Sample Size and Sampling Procedure}

The sample size was determined by using a double population formula by considering the following assumptions: 
95\% CI, 5\% margin of error, and the value of " $p$ " ( $p=$ proportion) were taken as prevalence of tested families of index cases among PLHIV, which was found to be $74.2 \%$, with proportion of outcome among exposed being $96.8 \%$ and that among non-exposed being $86.8 \%{ }^{10}$

Accordingly, the calculated sample size with a $10 \%$ non-response rate for this study was 348. For each ART clinic, the 3 months ART follow-up reports were compiled from ART registers and the average of the 3 months report was computed; and the expected number of patients attending each ART clinic per month were 230 in kule-1, 296 in kule-2, and 222 in kule-3, respectively. The sample size was allocated proportionally for the three sites and selected by using systematic random sampling. Since the total sample size for this study was 348, $\mathrm{k}=748$ / $348=2.14=2$. A lottery method was used to determine every first or second case. Therefore, every first client from the first two patients who came for ART services was selected systematically as a study participant.

\section{Operational Definition}

Index cases: Individuals diagnosed HIV positive who awere already enrolled in HIV care and treatment (21).

Tested family of index case: Either partner/spouse or children $<15$ years of age tested for HIV.

\section{Data Collection Tools and Procedure}

The standardized data collection tool was developed through reviewing related literature $(21,32)$. It contains information on socio-demographic, index case health status related factors, partner related factors, and institutional related factors.

First the questionnaire was prepared in English, translated to Nuer language, and then translated back to English in order to ensure its consistency. A week before the beginning of the actual data collection, a pre-test was done on $5 \%$ of the sample size in punido-two refugee camp. Feedback from both participants of the pre-test and data collectors was incorporated to enrich the questionnaire. The data were collected by three case managers and supervised by one health officer who was trained on HIV/AIDS comprehensive management and care. Training was given for data collectors and supervisors for how to manage the data collection process. All of the data collectors had completed grade ten and above. The data were collected by face-to-face interview and reviewing patient follow-up charts by using an interviewer-administered semi-structured questionnaire. Proper information was given for each participant on the purpose and usefulness of the study and, after getting verbal consent, interviewing respondents were cascaded based on the questionnaire.

\section{Data Processing and Analysis}

Data were entered into Epidata version 3.1 and then exported to SPSS version 23 for further analysis. Descriptive analyses like percentage, frequency, and mean were calculated. Bivariate and Multivariable logistic regression analyses were used to identify the presence of associations between dependent and independent variables. Bivariate analysis variables with $p \leq 0.25$ were entered into multivariable logistic regression analysis. The Hosmer-Lemeshow test was used to check the appropriateness of the model for analysis. The possible effects of confounders were controlled through multivariable logistic regression analysis. The association between the explanatory and dependent variables was assessed at the $p$-value of 0.05 . The variables that show a $p$-value $<0.05$ were declared as statistically significant variables in multivariable logistic regression analysis. The degree of association between independent and dependent variables was assessed using crude odd ratio (COR) and adjusted odds ratio (AOR) for bivariate and multivariable logistic regression, respectively, with a $95 \%$ confidence interval.

\section{Results}

Socio-Demographic \& Health status of study participants Out of 348 study participants, 339 (97.4\%) participated in this study. The mean age of the study participants was 43 years $(\mathrm{SD}= \pm 11.2)$, with a minimum age of 21 years and a maximum age of 70 years. Among the respondents, 214 $(63.1 \%)$ were female and $268(79.1 \%)$ were protestant religion followers. Two-thirds of the study participants $(283 ; 83.5 \%)$ were married. With regard to their educational status, $181 \quad(53.4 \%)$ were unable to read. The majority of the participants $(218,64.3 \%)$ were tested before 1 year, $206(60.8 \%)$ stayed on ART for greater than 1 year, and $120(35.4 \%)$ were on clinical stage III. In total, 185 (54.6\%) had good ART adherence (Table 1).

\section{Family-Related Characteristics}

One hundred and sixty one $(56.9 \%)$ respondents were living with their current partner for 5 or more years. Two hundred and thirteen of the study participants $(62.8 \%)$ had not discussed HTC with family members and 158 (46.6\%) of the participants had disclosed their HIV status to their family members (Table 2). 
Table I Socio-Demographic Characteristics and Health Status of Index HIV Cases Attending ART Clinics at Kule Refugee Camp, Southwestern Ethiopia 202I ( $n=339)$

\begin{tabular}{|c|c|c|c|}
\hline Variable & Category & Frequency & Percent \\
\hline \multirow[t]{3}{*}{ Sex } & & & \\
\hline & Male & 125 & $36.9 \%$ \\
\hline & Female & 214 & $63.1 \%$ \\
\hline \multirow[t]{5}{*}{ Age } & & & \\
\hline & $18-29$ & 37 & $10.9 \%$ \\
\hline & $30-39$ & 102 & $30.1 \%$ \\
\hline & $40-49$ & 104 & $30.7 \%$ \\
\hline & $>50$ & 96 & $28.3 \%$ \\
\hline \multirow[t]{3}{*}{ Marital status } & & & \\
\hline & Married & 283 & $83.5 \%$ \\
\hline & Other than & 56 & $16.5 \%$ \\
\hline \multirow[t]{4}{*}{ Educational level } & & & \\
\hline & $\begin{array}{r}\text { Unable to } \\
\text { read and } \\
\text { write }\end{array}$ & 181 & $53.4 \%$ \\
\hline & Primary level & 94 & $27.7 \%$ \\
\hline & $\begin{array}{l}\text { Secondary } \\
\text { and above }\end{array}$ & 64 & $18.9 \%$ \\
\hline \multirow[t]{4}{*}{ Religion } & & & \\
\hline & Protestant & 268 & $79.1 \%$ \\
\hline & Wundeng & 48 & $12.7 \%$ \\
\hline & other & 28 & $8.2 \%$ \\
\hline \multirow[t]{3}{*}{$\begin{array}{l}\text { Had children aged } \\
\text { less than } 15 \text { years }\end{array}$} & & & \\
\hline & Yes & 312 & $92 \%$ \\
\hline & No & 27 & $8 \%$ \\
\hline \multirow[t]{3}{*}{$\begin{array}{l}\text { Duration of index } \\
\text { client tested }\end{array}$} & & & \\
\hline & $<1$ year & 121 & $35.7 \%$ \\
\hline & $\geq 1$ year & 218 & $64.3 \%$ \\
\hline \multirow[t]{3}{*}{$\begin{array}{l}\text { Duration of index } \\
\text { client on ART }\end{array}$} & & & \\
\hline & $<1$ year & 133 & $39.2 \%$ \\
\hline & $\geq 1$ year & 206 & $60.8 \%$ \\
\hline \multirow[t]{4}{*}{$\begin{array}{l}\text { Functional Status of } \\
\text { index client }\end{array}$} & & & \\
\hline & Working & 220 & $64.9 \%$ \\
\hline & Bedridden & 11 & $3.2 \%$ \\
\hline & Ambulatory & 108 & $31.9 \%$ \\
\hline \multirow[t]{4}{*}{ WHO Clinical stage } & & & \\
\hline & Stage I & 112 & $33 \%$ \\
\hline & Stage II & 107 & $31.6 \%$ \\
\hline & Stage III & 120 & $35.4 \%$ \\
\hline
\end{tabular}

(Continued)
Table I (Continued).

\begin{tabular}{|l|r|r|r|}
\hline Variable & Category & Frequency & Percent \\
\hline $\begin{array}{l}\text { ART adherence status } \\
\text { of index client }\end{array}$ & & & \\
& Good & 185 & $54.6 \%$ \\
& Fair & 88 & $26.0 \%$ \\
& Poor & 66 & $19.4 \%$ \\
\hline Have sexual partner & & & \\
other than current & & & \\
& Yes & 92 & $32.5 \%$ \\
& No & 191 & $67.5 \%$ \\
\hline Used substance & & & \\
& Yes & 184 & $54.3 \%$ \\
& No & 155 & $45.7 \%$ \\
\hline
\end{tabular}

\section{Health Facility-Related Characteristics}

Most of the study participants (61.9\%) were first tested by provider-initiated HIV testing and counseling (PICT) and $233(68.7 \%)$ were counseled to bring their family for HIV testing at the ART clinic where they enrolled (Table 3).

\section{Proportion of HIV Tested Families of Index Clients}

From the total participants, $167(49.3 \%, 95 \% \mathrm{CI}=43.8$ $55.5 \%$ ) had tested their family members for HIV.

\section{Factors Associated with Index HIV Case Family Testing}

Bi-variable analysis was performed to identify candidate variables for the final model. Those variables which have a $p$-value below 0.25 were candidates for multivariable logistic regression analysis. The bi-variable analysis showed that age, education status, duration since the index case was tested, duration of index case on ART, WHO clinical stage, ART adherence, discussion about HTC, HIV status disclosure, method of HIV index client tested, and index case trusting to health professional to keeptheir privacy were candidate variables in the multiple logistic regression analysis.

After adjusting for possible confounding variables, a multivariable analysis showed that having an educational level of primary and above, being on ART for greater than 1 year, having good ART adherence status, having disclosed status to family members, and respondent tested 
Table 2 Family-Related Characteristics of Index Case Family Testing Among Adults Attending ART Clinics at Kule Refugee Camp, Southwestern Ethiopia, $2021 \quad(n=339)$

\begin{tabular}{|c|c|c|}
\hline Variable & Frequency & Percent \\
\hline \multicolumn{3}{|l|}{$\begin{array}{l}\text { Duration living together with } \\
\text { current partner }\end{array}$} \\
\hline$<5$ years & 122 & $43.1 \%$ \\
\hline$\geq 5$ years & 161 & $56.9 \%$ \\
\hline \multicolumn{3}{|l|}{$\begin{array}{l}\text { Discussion about HTC with family } \\
\text { member }\end{array}$} \\
\hline Yes & 126 & $37.2 \%$ \\
\hline No & 213 & $62.8 \%$ \\
\hline \multicolumn{3}{|l|}{$\begin{array}{l}\text { Disclosed HIV status to one family } \\
\text { member }\end{array}$} \\
\hline Yes & 158 & $46.6 \%$ \\
\hline No & 181 & $53.4 \%$ \\
\hline \multicolumn{3}{|l|}{ Method of disclosure } \\
\hline Self-disclosure & 23 & $14.6 \%$ \\
\hline Assisted disclosure & 51 & $32.3 \%$ \\
\hline Health worker disclosure & 84 & $53.1 \%$ \\
\hline \multicolumn{3}{|l|}{ Reason for non-disclosure to partner } \\
\hline Fear of perceived self-stigma & 107 & $57.2 \%$ \\
\hline Fear of divorce or separation & 98 & $54.1 \%$ \\
\hline Fear of intimate partner violence & 79 & $43.6 \%$ \\
\hline Other & 23 & $12.7 \%$ \\
\hline \multicolumn{3}{|l|}{$\begin{array}{l}\text { Reason for non-disclosure to own } \\
\text { children }\end{array}$} \\
\hline Children will ask me source of infection & 60 & $3.8 \%$ \\
\hline $\begin{array}{l}\text { Children will disclose my status to } \\
\text { other }\end{array}$ & 121 & $66.6 \%$ \\
\hline $\begin{array}{l}\text { I do not want to worry/upset my } \\
\text { children }\end{array}$ & 159 & $87.8 \%$ \\
\hline Children may not understand it & 177 & $94.7 \%$ \\
\hline Other & 41 & $22.6 \%$ \\
\hline
\end{tabular}

through VCT were identified to be significantly associated with index case family testing.

The results of multivariable analysis revealed that respondents who attended primary level education had tested their families were 2.4-times ( $\mathrm{AOR}=2.4,95 \%$ $\mathrm{CI}=1.24-4.4)$ more likely than those who were not able to read and write. Also those who had attended secondary level education were 2.6-times more likely to have their family tested for HIV AIDS (AOR $=2.6$, 95\% CI $=1.32$ 4.72) than those who were unable to read and write. Index clients who received ART for more than 1 year were twice as likely to test their family for HIV than index clients who received ART for less than 1 year (AOR=2.0, 95\%, $\mathrm{CI}=1.10-3.20)$.
Table 3 Health Facility-Related Factors for Index Case Family HIV Testing Among Adult Index Cases Attending ART Clinic at Kule Refugee Camp, 2021 ( $n=339)$

\begin{tabular}{|c|c|c|}
\hline Variable & Frequency & Percent \\
\hline \multicolumn{3}{|l|}{$\begin{array}{l}\text { Index client first HIV testing } \\
\text { approach }\end{array}$} \\
\hline Voluntary counseling and testing (VCT) & 108 & $31.9 \%$ \\
\hline $\begin{array}{l}\text { Provider-initiated counseling and testing } \\
\text { (PICT) }\end{array}$ & 210 & $61.9 \%$ \\
\hline Index case testing (ICT) & 21 & $6.2 \%$ \\
\hline \multicolumn{3}{|l|}{$\begin{array}{l}\text { Counseled to bring families for HIV } \\
\text { testing }\end{array}$} \\
\hline Yes & 233 & $68.7 \%$ \\
\hline No & 106 & $31.3 \%$ \\
\hline \multicolumn{3}{|l|}{$\begin{array}{l}\text { Trust in ART clinic staff } \\
\text { (confidentiality) }\end{array}$} \\
\hline Yes & 251 & $74 \%$ \\
\hline No & 84 & $26 \%$ \\
\hline \multicolumn{3}{|l|}{ Preferred time for HIV testing } \\
\hline Regular working hours & 268 & $79.1 \%$ \\
\hline Evening & 13 & $3.8 \%$ \\
\hline Weekend/holidays & 58 & $17.1 \%$ \\
\hline \multicolumn{3}{|l|}{ Preferred place for HIV testing } \\
\hline Health facility-based & 232 & $68.4 \%$ \\
\hline Community-based & 36 & $10.6 \%$ \\
\hline Home-based & 71 & $20.9 \%$ \\
\hline
\end{tabular}

Respondents who discussed HTC with their families were 3.6-times more likely to test for HIV within their family (AOR=3.6, 95\% $\mathrm{CI}=1.30-10.30)$ than their counterparts. Participants who had good ART adherence were 6-times more likely to test their family for HIV compared to their counterparts $(\mathrm{AOR}=6.0,95 \% \mathrm{CI}=2.80-14.10)($ Table 4$)$.

\section{Discussion}

This study tried to assess the proportion of tested family members of index cases for HIV among adults currently attending ART clinics at Kule Refugee Camp in Gambela region. This study showed that $167(49.3 \%, 95 \% \mathrm{CI}=43.8-$ $55.5 \%$ ) families of index case were tested for HIV.

This finding is lower than a studies conducted in Felege Hiwot referral hospital Bahir Dar, Ethiopia (74.2\%), ${ }^{10}$ Kenya $(62 \%),{ }^{11}$ Nigeria $(93.2 \%),{ }^{12}$ Uganda $(93 \%),{ }^{13}$ Cameroon $(71.5 \%),{ }^{14}$ Malawi, $(92.6 \%),{ }^{15}$ and Tanzania $(96.0 \%) .{ }^{16}$ The possible justification of this difference might be due to sampling difference. In Uganda and Nigeria, index cases were admitted patients, so families of index cases might be 
Table 4 Bi-Variable and Multi-Variable Analysis of Factors Associated with Index HIV Case Family Testing Among Adults Attending ART Clinic at Kule Refugee Camp, 202I

\begin{tabular}{|c|c|c|c|c|c|c|}
\hline \multirow[t]{2}{*}{ Variable } & \multirow[t]{2}{*}{ Category } & \multicolumn{2}{|c|}{ Family Tested } & \multirow[t]{2}{*}{ COR $(95 \% \mathrm{Cl})$} & \multirow[t]{2}{*}{ AOR (95\% CI) } & \multirow[t]{2}{*}{$p$-value } \\
\hline & & Yes & No & & & \\
\hline \multirow[t]{4}{*}{ Age } & $18-29$ & 25 & 12 & $2.20(1.04-5.00)$ & $2.4(0.97-6.18)$ & 0.580 \\
\hline & $30-39$ & 41 & 61 & $0.63(0.35-1.11)$ & $0.6(0.32-1.27)$ & 0.200 \\
\hline & $40-49$ & 58 & 46 & $1.50(0.85-2.64)$ & I.4 (0.73-2.85) & 0.300 \\
\hline & $\geq 50$ & 43 & 53 & I & I & 1 \\
\hline \multirow[t]{3}{*}{ Educational status } & Unable to read and write & 77 & 104 & I & I & 1 \\
\hline & Primary level educate & 53 & 41 & $1.7(1.14-3.14)$ & $2.4(1.24-4.42)^{*}$ & 0.008 \\
\hline & Secondary and above & 37 & 27 & $1.9(1.32-4.17)$ & $2.6(1.20-4.42)^{*}$ & 0.013 \\
\hline \multirow[t]{3}{*}{ WHO stage } & Stage I & 54 & 58 & I & 1 & 1 \\
\hline & Stage 2 & 45 & 62 & $0.8(0.46-1.30)$ & $0.6(0.30-1.40)$ & 0.211 \\
\hline & Stage 3 & 68 & 52 & $1.4(0.84-2.40)$ & $0.5(0.74-3.12)$ & 0.444 \\
\hline \multirow[t]{2}{*}{ Duration since index client tested } & $<$ l year & 44 & 73 & I & I & 1 \\
\hline & $\geq$ I year & 123 & 99 & $2.1(1.3-3.3)$ & I (0.64-I.87) & 0.600 \\
\hline \multirow[t]{2}{*}{ Years on ART } & $<$ l year & 48 & 85 & I & I & 1 \\
\hline & $\geq$ I year & 119 & 87 & $2.4(1.6-3.8)$ & $2.0(1.1-3.2)^{*}$ & 0.001 \\
\hline \multirow[t]{3}{*}{ Functional status } & Working & 100 & 120 & $0.60(0.4-0.95)$ & $0.8(0.40-1.62)$ & 0.570 \\
\hline & Ambulatory & 63 & 45 & $0.40(0.11-1.50)$ & $1.3(0.60-3.01)$ & 0.500 \\
\hline & Bedridden & 4 & 7 & I & & 1 \\
\hline \multirow[t]{3}{*}{ Adherence status } & Good & 115 & 70 & $7.4(3.7-14.8)$ & $6(2.8-14.1)^{*}$ & 0.001 \\
\hline & Fair & 40 & 48 & $3.8(1.8-8.0)$ & $2.3(1.04-5.7)^{*}$ & 0.040 \\
\hline & Poor & 12 & 54 & 1 & I & 1 \\
\hline \multirow[t]{2}{*}{ Discussion about HIV testing } & Yes & 76 & 50 & $2(1.3-3.2)$ & $3.6(1.3-10.3)^{*}$ & 0.013 \\
\hline & No & 91 & 122 & 1 & I & I \\
\hline \multirow[t]{2}{*}{ Disclosure status to family } & Yes & 101 & 57 & $3(2.0-4.8)$ & $6.0(2.21-16.90)^{*}$ & 0.001 \\
\hline & No & 66 & 115 & I & I & 1 \\
\hline \multirow[t]{3}{*}{ Index client first tested through } & VCT & 68 & 40 & $2.4(1.5-3.8)$ & $3.0(1.70-5.70)^{*}$ & 0.001 \\
\hline & PICT & 88 & 122 & I & 1 & 1 \\
\hline & ICT & 11 & 10 & $1.5(0.6-3.8)$ & $2(0.70-6.60)$ & 0.200 \\
\hline \multirow[t]{2}{*}{ Trusting professional on keeping privacy } & Yes & 130 & 123 & $1.4(0.86-2.3)$ & I.3 $(0.56-2.00)$ & 0.86 \\
\hline & No & 37 & 49 & I & I & I \\
\hline
\end{tabular}

Note: *Statistically significant.

cooperative to accept testing than in a study where index cases were on outpatient follow-up. Additionally, there is a difference in study area. This study was conducted in a refugee camp where HIV testing is less of a priority issue. Poor healthcare services, limited availability of skilled health workers who understand both languages, and the customs of 
the refugees might decrease the motivation to be tested among family members.

Multivariable analysis of this study revealed that the educational status of index HIV cases, the duration of index cases on ART, having discussions about HIV testing with family member, HIV disclosure status, ART adherence, and index cases testing approach were identified as factors significantly associated with index HIV case family testing.

In this study, respondents who attended an educational level of primary and above had a higher number of tested family members than respondents who were unable to read and write. This finding is in line with the national level EDHS2016 study. The results showed the better-educated individuals were more likely to have comprehensive HIV knowledge. HIV testing coverage increases with rising level of education, from $14 \%$ of women with no education to $44 \%$ among women with more than secondary education. Among men, the HIV testing varies from $13 \%$ among those with no education to $39 \%$ among those with more than secondary education level. ${ }^{9}$ Continued exposure to HIV prevention information is more freely available in school systems than in the community. ${ }^{9}$ Educated individuals were found to be more knowledgeable on the benefits of family testing, had improved recognition of the importance of knowing one's HIV status, and, in this study setting practically, refugees who had a better education level had opportunities to be employed by different organizations as an incentive worker, which might increase the decisionmaking role on utilization of testing their families.

On the other hand, this study revealed that the odds of the index case's family testing was higher among respondents who had disclosed their HIV status to their family members compared to those who had not disclosed their HIV status. This finding is consistent with studies conducted in Assosa, Ethiopia, ${ }^{18}$ Uganda, ${ }^{19}$ and Zambia. ${ }^{20,21}$ The reason for this could be that disclosure of HIV positive status plays an important role for both to the infected individual and to the family at large. It adequately addresses emotional, social, and practical consequences of the disease among the families. ART services require that patients should have to disclose their HIV positive status to their treatment supporters. This inspires families to seek HIV testing and counseling, so is a key issue for the further step of telling a spouse to get tested for HIV, and creates a favorable environment by reducing stigma and encouraging trust among families. Due to this, the families of index clients will be cooperative in being tested and knowing their HIV status.
This finding showed that discussing HIV testing with family members is significantly associated with testing of family members. This is similar with studies conducted in Mekelle hospital, Ethiopia, ${ }^{21}$ Felege Hiwot Referral Hospital, Ethiopia, ${ }^{10}$ and Ndola, Zambia. ${ }^{15}$ The possible reason for this association is that discussion about testing is a pre-condition for tracing family members for testing and results in a favourable situation for the index client to bring their families for testing.

This study also revealed that participants who had good ART adherence were more likely to test at least one family member than those who had poor ART adherence. This finding is consistent with the findings from Kenya ${ }^{11}$ and Uganda. ${ }^{12}$

This might be due to adherence to treatment being critical to maintain the health status of the index client by addressing issues of disclosure, stigma, confidentiality, and deeply held belief systems. Adhering to ART might enhance frequently visiting the ART clinic as scheduled. Repeated exposure to counseling might increase the level of awareness and health status of the client. So, respondents who had good ART adherence were more likely to disclose their HIV positive status which results in the fact that it made them more likely to get their partner and children tested. ${ }^{22}$

This study also shows that respondents who stayed on ART for $\geq 12$ months were 2-times more likely to test their partner and children compared to respondents who stayed on ART for $<12$ months. This finding is consistent with a study done in Cameroon, whereparents who had been on ART for more than 5 years were twice as likely to test at least one family member compared to those who had been on ART for less than 5 years. ${ }^{17}$ This might be due to the barriers to initiation on HIV treatment and retention in care. Self-perceived stigma and discrimination is higher among newly-initiated clients. ${ }^{15}$ The longer the duration of being on ART treatment, it is expected that the level of awareness of HTC will increase and disclosing status to family becomes more likely, which facilitates testing of families.

In this study setting, since refugees are mobile, those who stayed on ART follow-up for greater than a year were more likely to have addressed social challenges by organization working on that and made respondents to bring families for testing than newly ART initiated clients. Additionally, participants who tested first by VCT had an almost 3-times higher odds of testing at least one member from partner and children when compared to those who were tested by PICT. This might be due to VCT being client-initiated testing and them coming for preventive HIV acquisition through risk assessment and 
risk reduction, compared to those tested through PICT who visited the health institution for another disease. ${ }^{6}$ These clients had limited time for counseling, with inappropriate space to counsel and recommend testing as a standard medical practice, and they might not be aware of HIV related issues and ready for testing. Therefore, they could not be well aware of the infection and its transmission to other persons, including family members.

\section{The Strength of the Study}

This study was conducted in a less studied study population.

It is the first study of its kind in the study area.

\section{The Limitations of the Study}

The study used verbal reporting of respondents about family member tracing for HIV, which may cause interviewers bias and social desirability bias.

\section{Abbreviations}

AOR, Adjusted Odds Ratio; HIV, Human Immunodeficiency Virus; ART, Antiretroviral Therapy; AIDS, Acquired Immunodeficiency Syndrome.

\section{Data Sharing Statement}

The data sets used/or analyzed during the current study are available from all authors (Yohannes wegu, Tesfaye Sileshi and Tamirat Melis) on reasonable request.

\section{Ethics and Consent}

Ethical clearance was obtained from Metu University, College of Medicine and Health Science, Institutional Ethical Review Board. By using a support letter which was approved by the Metu University Institutional Ethical Review Board, department of public health, permission to conduct the research was obtained from Gambela region health office, Kulle Refugee Camp. Verbal informed consent was obtained from study participants and approved by the ethical committee. The study was conducted according to the Declaration of Helsinki. Respondents were informed about the purpose and procedure of the study, the importance of their participation, the right to withdraw at any time if they want privacy and confidentiality, as the information given by each respondent was kept properly and names were not recorded.

\section{Acknowledgment}

We would like to express our heartfelt appreciation to data collectors and all ART patients who were involved as study participants in this study. We are also grateful to all health professionals who supported the study process.

\section{Author Contributions}

YW, TS, and TM made substantial contributions to the conception and design, acquisition of data, or analysis and interpretation of data; took part in drafting the article or revising it critically for important intellectual content; agreed to submit to the current journal; gave final approval of the version to be published; and agree to be accountable for all aspects of the work.

\section{Funding}

There is no funding to report.

\section{Disclosure}

The authors declare that they have no competing interests.

\section{References}

1. Lemma E, Husein G. Male partner involvement on prevention of mother to child transmission of HIV and associated factors among pregnant mothers attending antenatal at Fantale District, Ethiopia. $J$ Women's Health Care. 2017;6(02):45.

2. Adewo T, Gemeda D, Ayele W. Male partner participation in preventing mother-to-child transmission of human-immunodeficiency virus (PMCHT) and its predictive factors in Bishoftu, Central Ethiopia. J Midwifery Reprod Health. 2018;6(4):1437-1446.

3. Teshome M. Male involvement in prevention of mother to child transmission of HIV in the context of partner HIV testing and associated factors at antenatal Care in Goba Town, Bale Zone Oromia Region, South East Ethiopia, Addis Ababa University; 2015.

4. Amano A, Musa A. Male involvement in PMTCT and associated factors among men whom their wives had ANC visit 12 months prior to the study in Gondar town, North west Ethiopia, December, 2014. Pan Afr Med J. 2016;24(1). doi:10.11604/pamj.201 6.24.239.8460

5. Belato DT, Mekiso AB, Begashaw B. Male partners involvement in prevention of mother-to-child transmission of HIV services in Southern Central Ethiopia: in case of Lemo District, Hadiya Zone. AIDS Res Treat. 2017;2017:35.

6. Tilahun M, Mohamed S. Male partners' involvement in the prevention of mother-to-child transmission of HIV and associated factors in Arba Minch Town and Arba Minch Zuria Woreda, Southern Ethiopia. Biomed Res Int. 2015;2015:57-59.

7. Adane HA, Assefa N, Mengistie B, Demis A. Male involvement in prevention of mother to child transmission of human immunodeficiency virus and associated factors in Enebsiesarmider District, north West Ethiopia, 2018: a cross-sectional study. BMC Pregnancy Childbirth. 2020;20(1):1-8. doi:10.1186/s12884-020-2837-y

8. Alemayehu M, Etana B, Fisseha G, Haileslassie K, Yebyo H. The role of male partner involvement on mother's adherence to PMTCT care and support, Tigray, Northern Ethiopia. Fam Med Med Sci Res. 2014;3 (04). doi:10.4172/2327-4972.1000137

9. Amsalu E, Tiruneh G, Abajobir AA. Level of male partner involvement and associated factors in prevention of mother to child transmission of HIV/AIDS services in Debremarkos town, Northwest Ethiopia. BMC Pediatr. 2013;10:16-25. 
10. Aluisio AR, Bosire R, Betz B, et al. Male partner participation in antenatal clinic services is associated with improved HIV-free survival among infants in Nairobi, Kenya: a prospective cohort study. $J$ Acquir Immune Defic Syndr. 2016;73(2):169. doi:10.1097/ QAI.0000000000001038

11. Joseph Davey D, Wall KM, Serrao C, et al. HIV positivity and referral to treatment following testing of partners and children of PLHIV index patients in public sector facilities in South Africa. J Acquir Immune Defic Syndr. 2019;81(4):365-370. doi:10.1097/ QAI.0000000000002048

12. Mohammed BH, Johnston JM, Vackova D, Hassen SM, Yi H. The role of male partner in utilization of maternal health care services in Ethiopia: a community-based couple study. BMC Pregnancy Childbirth. 2019;19(1):1-9. doi:10.1186/s12884-019-2176-z

13. Haile T, Gulema H. Assessment of the proportion and the factors associated with partner and family based index case HIV testing in Woliso town, Oromia, Ethiopia: a cross-sectional study. BMC Public Health. In Press 2020.

14. Sanga Z, Kapanda G, Msuya S, Mwangi R. Factors influencing the uptake of voluntary HIV counseling and testing among secondary school students in Arusha City, Tanzania: a cross sectional study. BMC Public Health. 2015;15:452. doi:10.1186/s12889-015-1771-9

15. Alexander RB, Boyer EW, Smith RA, Schwarz GE, Moore RB. The role of headwater streams in downstream water quality 1. JAWRA. 2007;43(1):41-59. doi:10.1111/j.1752-1688.2007.00005.x
16. HIV/AIDS (UNAIDS) JUNPo. The prevention gap report; 2016.

17. Kabanga E, Chibwae A, Basinda N, Morona D. Prevalence of male partners involvement in antenatal care visits-in Kyela district, Mbeya. BMC Pregnancy Childbirth. 2019;19(1):1-6. doi:10.1186/ s12884-019-2475-4

18. Dalal S, Johnson C, Fonner V, et al. Improving HIV test uptake and case finding with assisted partner notification services. Aids. 2017;31 (13):1867-1876. doi:10.1097/QAD.0000000000001555

19. Uehara M. A literature review on male involvement in HIV testing and counseling among pregnant women in Sub-Saharan Africa; 2012.

20. Wamuti BM, Erdman LK, Cherutich P, et al. Assisted partner notification services to augment HIV testing and linkage to care in Kenya: study protocol for a cluster randomized trial. Implement Sci. 2015;10:23. doi:10.1186/s13012-015-0212-6

21. Cheruiyot C, Magu D, Mburugu P, Sagwe D. Uptake and utilization of institutional voluntary HIV testing and counseling services among students aged 18-24 in Kenya's public Universities. Afr Health Sci. 2019;19(4):3190-3199. doi:10.4314/ahs.v19i4.42

22. Hlongwa M, Mashamba-Thompson T, Makhunga S, Hlongwana K. Barriers to HIV testing uptake among men in sub-Saharan Africa: a scoping review. Afr J AIDS Res. 2020;19(1):13-23. doi:10.2989/ 16085906.2020 .1725071
HIV/AIDS - Research and Palliative Care

\section{Publish your work in this journal}

HIV/AIDS - Research and Palliative Care is an international, peerreviewed open-access journal focusing on advances in research in HIV, its clinical progression and management options including antiviral treatment, palliative care and public healthcare policies to

\section{Dovepress}

control viral spread. The manuscript management system is completely online and includes a very quick and fair peer-review system, which is all easy to use. Visit http://www.dovepress.com/testimonials.php to read real quotes from published authors. 